Vamos encerrar com os votos de pleno sucesso à Hemobrás e que o Brasil se torne auto-suficiente em hemoderivados com produtos de qualidade e preços compatíveis.

Professor Livre-docente de Hematologia - Unifesp-SP

Ex-presidente da SBHH (1979-1981)/ (1998-2000)

Correspondência para: Celso C. C. Guerra

Av. Brasil, 1640 - J. América

01430-001 - São Paulo - SP

Tel.: (11) 853-4555 / 853-6611 - Fax: (11) 858-2025

E-mail: chspdire@ruralsp.com.br

Avaliação: $\mathrm{O}$ tema abordado foi sugerido e avaliado pelo editor. Conflito de interesse: não declarado

Recebido: 10/03/05

Aceito: 11/03/05

\section{Bussulfano e ciclofosfamida no condicionamento do transplante de medula óssea para anemia aplástica grave}

\section{Frederico Luiz Dudley}

A idéia de se utilizar o bussulfano em associação com a ciclofosfamida no condicionamento do transplante de medula óssea (TMO) da anemia aplástica grave é brasileira e data de 1993, sendo utilizado pela primeira vez no Hospital das Clínicas da Faculdade de Medicina da Universidade de São Paulo. ${ }^{1}$ Naquela época tínhamos um índice de rejeição de 50\% nos pacientes condicionados somente com ciclofosfamida na dose de $200 \mathrm{mg} / \mathrm{kg}$.

A adição de bussulfano $4 \mathrm{mg} / \mathrm{kg}$ em um dia baixou a taxa de rejeição para $12,5 \%$ no nosso serviço. Um trabalho cooperativo envolvendo as unidades de transplante de medula óssea da Universidade de São Paulo, da Unicamp e da Faculdade de Medicina de São José do Rio Preto, ${ }^{2}$ usando este tipo de condicionamento em 81 pacientes, mostrou que a taxa cumulativa de rejeição foi de $22 \%$. Para os pacientes com mais de 50 transfusões previamente ao transplante, a taxa de rejeição foi de $43 \%$ comparada a $16 \%$ para os pacientes com menos do que 50 transfusões $(p=0,06)$.

A sobrevida global até oito anos após o TMO foi de $56 \%$, sendo de $78 \%$ para pacientes que receberam $\leq 15$ transfusões antes do transplante e de $50 \%$ para os que receberam mais do que 15 transfusões $(\mathrm{p}=0,01)$. Entretanto, a sobrevida foi de $67 \%$ para quem recebeu $\leq 50$ transfusões antes do transplante e de $28 \%$ para os que receberam mais do que 50 transfusões $(\mathrm{p}=0,002)$.

$\mathrm{Na}$ análise multivariada, o grande número de transfusões antes do transplante, um período mais curto de imunossupressão até a retirada da ciclosporina (180 dias) e a presença da doença do enxerto contra o hospedeiro foram associados com a pior sobrevida neste grupo. Portanto, a adição do bussulfano em baixa dose à ciclofosfamida no condicionamento da anemia aplástica grave pode ajudar a melhorar a sobrevida, diminuindo a taxa de rejeição para aqueles pacientes que receberam até 50 transfusões antes do TMO.

Recomenda-se também que a ciclosporina, se possível, seja mantida até dois anos após o TMO.

No trabalho de Silva e Pasquini, apresentado nesta edição, observa-se algo semelhante ao que foi dito, com alta rejeição nos pacientes condicionados somente com $200 \mathrm{mg} / \mathrm{kg}$ de ciclofosfamida (46\%) e de $12 \%$ nos condicionados com bussulfano na dose de $12 \mathrm{mg} / \mathrm{kg}$ associado à ciclofosfamida $120 \mathrm{mg} / \mathrm{kg}$.

Também a sobrevida dos pacientes politransfundidos foi baixa, em torno de $35 \%$. Portanto, a idéia de se utilizar o bussulfano no condicionamento da anemia aplástica grave é original, inédita, brasileira e mostrou ter diminuído a taxa de rejeição no transplante de medula óssea da anemia aplástica grave.

\section{Referências Bibliográficas}

1. Dulley FL. Bussulfano e ciclofosfamida como condicionamento para o transplante de medula óssea da anemia aplástica grave. São Paulo, 2.000. Tese de Livre Docência - Departamento de Clínica Médica da Faculdade de Medicina da Universidade de São Paulo.

2. Dulley FL, Vigorito AC, Aranha FJP et al. Addition of low dose busulfan to cyclophosphamide in aplastic anemia patients prior to allogeneic bone marrow transplantation to reduce rejection. Bone Marrow Transplantation 2004;3:9-13.

Professor Livre-Docente da Faculdade de Medicina da Universidade de São Paulo.

Chefe do Serviço de Transplante de Medula Óssea do Hospital das Clínicas da Faculdade de Medicina da Universidade de São Paulo.

Correspondência para: Frederico Luiz Dudley

Rua Barata Ribeiro, 380 - CJ 84 - Cerqueira César

01308-000 - São Paulo-SP

E-mail: onco@csf.com.br/fldulley@usp.br

Avaliação: O tema abordado foi sugerido e avaliado pelo editor. Conflito de interesse: não declarado

Recebido: 07/03/05

Aceito: 11/03/05 